ecstasy of Good Friday " wept tears of blood. This was regarded as a hysterical manifestation.

The main point of interest in my case is that the source of the ' haemorrhage could be so definitely demonstrated. A case of severe haemorrhage from an ulcerated naevus leading to a state of collapse was recorded by Jessop in 1898 .

Apart from injury bleeding from the conjunctiva must be a somewhat rare occurrence. In the course of a very long experience in an industrial area I have never met with this before. I have everted thousands of eyelids in a population exposed to frequent minor injuries, and I have never seen a capillary angioma situated on the palpebral conjunctiva which could be attributed to trauma. It is unlikely, therefore, that this angioma had any association with injury.

I am indebted to Professor Loewenstein for his histological notes and to Mr. John Watt for his technical assistance. My thanks are also due to Professor W. J. B. Riddell for kindly placing the resources of the Tennent Institute at my disposal.

\title{
BIBLIOGRAPHY
}

HyUex. KonNersReuth (Trans. Shepherd), London, 1932.

JESSOP.-Trans. Ophthal. Soc. U.K., Vol: XV, p. 64, 1895.

\section{A CORNEAL GRAFT OPERATION FOR RECURRENT PTERYGIUM*}

BY

Lieut. J. L. REIS, Polish A.M.C.

OPHTHALMIC SPECIALIST, POLISH

GENERAL HOSPITAL, C.M.F.

THE common methods of pterygium operations aim at the separation and displacement of the pterygium from the cornea. This leaves an open wound of the cornea, where a cicatricial opacity, with tendency to vascularisation; develops. It is not unusual for this corneal scar to get covered with conjunctiva, thus forming a pseudopterygium.

Not infrequently the pterygium recurs and has the same appearance as the stationary pseudopterygium but differs from the latter by its tendency to grow and that it has no marginal folds. So the results of those operations are not very satisfactory, both from the cosmetic as well as from the functional point of view.

* Received for publication April 19, 1945. 
Some authors, basing their views on the pathology of pterygium - which shows corneal dystrophy rather than conjunctival hypertrophy-use a corneal graft to cover that part of the cornea from which the pterygium has been removed. This procedure gives not only better optical and cosmetic results, but also seems to prevent recurrences.

Magitot of Paris,* about 20 years ago, published his method of taking a corneal graft from the upper part of the affected cornea. After separation of the pterygium from the cornea he prepares a conjunctival flap covering the part of cornea affected by the pterygium. Then, using a trephine, he mákes a semi-circular superficial incision with its base upwards on the upper part of the cornea, close to the limbus. Next he separates with a special knife a flap of the superficial layers of the cornea. Finally he slides the corneal graft thus obtained to that part of cornea from which the pterygium was removed, and under the previously prepared conjunctival flap.

Filatov in Russia performs a similar operation, taking corneal grafts from other eyes, even those of fresh corpses.

These superficial corneal yraft operations in pterygium cases have so far not been commonly used ; perhaps because conjunctival sepsis impaired the results in a proportion of cases. At present we are in a much more fortunate position than we were some years ago, being equipped with powerful bacteriostatics such as sulphonamides and penicillin, and therefore being able to expect much better results from corneal grafts.

The operation which I have performed is based on the method described above. It can be undertaken when an opportunity occurs of enucleating an eyeball which has a reasonable cornea in a healthy patient. The enucleation is performed just before the pterygium operation and the excised eyeball put into a sterile 1 per cent. saline solution.

Usual anaesthesia consists of 5 per cent. cocaine instillations and a subconjunctival injection of novutox-adrenalin solution. The first stage of operation is a modified McReynolds method. After a deep dissection of the pterygium from the cornea with a Graefe knife, the conjunctiva is separated from the limbus and undermined more widely than in the usual McReynolds operation. After fixing the head of the pterygium in the subconjunctival pocket, a stitch is inserted joining the lower limbal margin of conjunctiva with the former upper margin of pterygium. It results in forming a conjunctival flap and stretching it over the corneal area previously covered by pterygium (diagram).

* As this paper is written abroad on active service, I have no access to original papers. It is also reported in Le pterygion, Merigot de Treigny, Bull. de la Soc. d'Ophtal. de Paris, 1933. 
Now with a Graefe's or Beer's knife a superficial corneal layer, from the enucleated eyeball is dissected, after its margins have been delimited by two parallel, superficial incisions. Its size will depend on extent of the denuded cornea to be covered, and will therefore vary from 3 to $5 \mathrm{~mm}$. This graft is transferred on the knife blade and slid on to the cornea of the recipient. Then the conjunctival flap is raised slightly with opened forceps and the

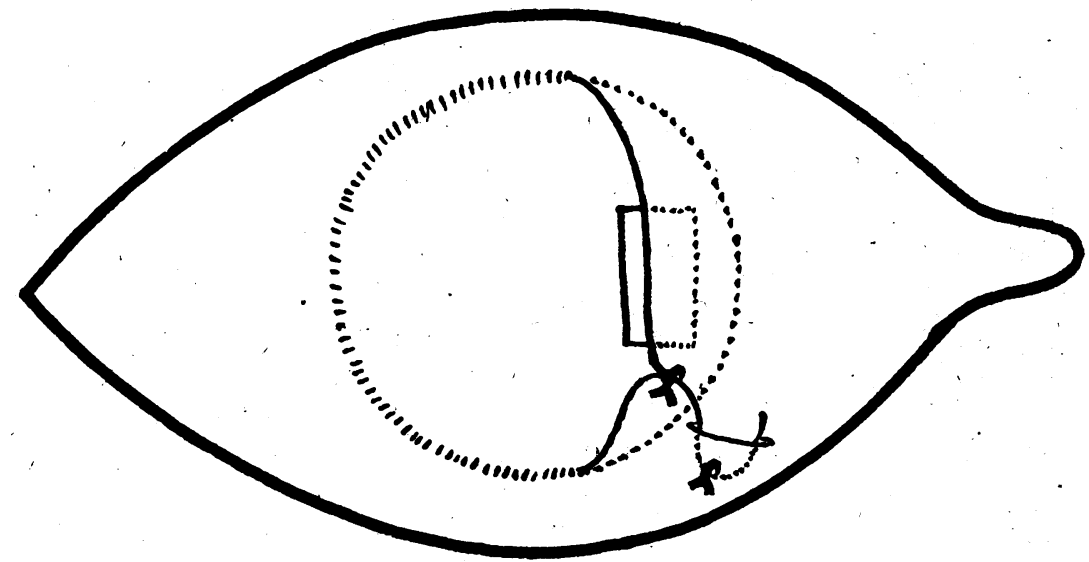

Modified McReynolds pterygium operation with corneal grafting.

graft is slid underneath. It is not essential that the conjunctival flap should cover the whole of the corneal graft.

After putting calcium penicillin-sulphathiazole powder into the conjunctival sac, both eyes are closed with a pad and bandage. The first dressing is done the next day and afterwards daily, atropine drops and penicillin solution are instilled. The unoperated eye is left open on the fourth day and sulphanilamide ointment is inserted twice daily instead of the penicillin powder. If the stitch forming the flap does not fall out itself, it is removed on the fourth day, the stitch holding the head of the pterygium can remain some days longer.

\section{Description of case}

$\mathrm{J}$. W., aged 44 years, male, noticed a pterygium on his right eye since 1939. In October, 1943, operation elsewhere. Recurrence of pterygium; operation again in March, 1944. I saw him for the first time on September 31, 1944, and found that his pterygium had again recurred.

Examination :-Left eye : normal, $V=6 / 5$. Right-eye: conjunctival fold covering $4 \mathrm{~mm}$. of cornea, reaching the pupillary 
area. Some superficial corneal opacities in advance of its head. Slight congestion of pterygium vessels. $V=6 / 12$ retinoscopy after homatropine : normal refraction with some irregular astigmatism caused by the pterygium : V. not improved by glasses.

October 20, 1944. Admission to hospital. Considering the size of the pterygium and in "view of the fact that delay might cause further increase of its size which would be very inadvisable as the pterygium had already reached the pupillary area, an operation with corneal graft was decided upon.

The donor of the corneal graft: K. R., aged 32 years, male, had a painful shrinking eye after a penetrating scleral wound. The cornea was -in good condition : Kahn test negative.' Blood grouping was A/II, same as recipient.

October 27, 1944. Operation and post-operative treatment as described above.

October 31, 1944: Conjunctival flap stitch fell out. Corneal graft in place. Slightly opaque. Hyperaemia of the conjunctiva. Monocular dressing.

November 11, 1944. Slight ciliary injection, corneal graft less opaque. 1 per cent. yellow mercuric oxide ointment used twice daily.

December 2, 1944 . Corneal graft almost clear; conjunctiva normal. $V=6 / 9$. Slit-lamp examination : Vascularisation of the corneal epithelium in the peripheral parts of graft. Small blood vessels going out from limbus seem to stop on the edge of the corneal graft.

Discharged from hospital.

March 7, 1945. Examination : Condition as on discharge from hospital.

\section{Summary}

(1) In cases of recurrent or advanced pterygium a partial corneal graft is indicated.

(2) A modified McReynolds pterygium operation is described, in which the denuded corneal area is covered by a corneal graft.

I have to thank Col. F. Balaszeskul, commanding officer of a Polish General Hospital, and Lieut.-Col. B. W. Rycroft, O.B.E., Adviser in Ophthalmology, A.F.H.Q., Central Mediterranean Forces, for permission to publish this paper, and I would like to express my gratitude to Major B. Gluck, R.A.M.C., for his great help and advice in its preparation. 